\title{
Malaria in the Limbé River valley of northern Haiti: a hospital-based retrospective study, 1975-1997
}

\author{
Tammy Vanderwal ${ }^{1}$ and Richard Paulton ${ }^{1}$
}

\begin{abstract}
In the Limbé River valley of northern Haiti a retrospective study at the Bon Samaritain Hospital (BSH) determined the total number of cases and the cyclical nature of malaria from 1975 through 1997, examined the relationship between rainfall and malaria from 1975 through 1985, and compared the incidence of malaria at that hospital with general trends for Haiti for 1975 through 1996 as reported by the World Health Organization (WHO).

During 1975-1997, 27078 positive cases of malaria were diagnosed at BSH; 50\% of these cases occurred during 16 weeks out of the year, during a summer peak in June and July and a winter peak in December and January. For 1975-1985, there was no significant correlation between the incidence of malaria and annual rainfall. The strongest correlation was observed between weekly rainfall and weekly incidence of malaria when the data was staggered to allow a lag of 9-11 weeks between rainfall and new malaria cases. The lag period is explained by the time required for the creation of breeding sites after rain, the life cycles of the Anopheles albimanus mosquito and the Plasmodium falciparum parasite, and the incubation period for falciparum malaria.

The incidence of malaria in the Limbé River valley loosely followed the trends in all of Haiti and also supported WHO reports indicating that malaria in Haiti has been in a general decline since the mid-1980s.

By showing the seasonal trends for malaria in the Limber valley and the relationship between rainfall and malaria over an extended time period, this study provides a means to measure the effectiveness of malaria control efforts in the region.
\end{abstract}

Haiti and the Dominican Republic occupy Hispaniola, the only island in the Caribbean where malaria still persists. Haiti is situated in the western third of the island, and $80 \%$ of the country's inhabitants live in areas where malaria is transmitted (1). Malaria in Haiti involves a single parasite species,

\footnotetext{
Trinity Western University, Department of Biology, Langley, British Columbia, Canada. Send correspondence to: Richard Paulton, Trinity Western University, Biology Department, 7600 Glover Road, Langley, British Columbia, Canada, V2Y 1Y1. Telephone: 16048887511 ext 3206; Fax: 1604513 2018; e-mail: paulton@twu.ca
}

Plasmodium falciparum, and one mosquito vector, Anopheles albimanus (2). To date, no significant resistance to chloroquine has been observed anywhere in Haiti, and standardized treatment with chloroquine is extremely effective. Control of malaria in Haiti is mainly limited to treatment with chloroquine; other eradication or control programs have been limited in scope and have often been left unfinished $(3,4)$

Haiti provides a unique opportunity to study the incidence of malaria caused solely by nonresistant $P$. falciparum. This present study shows the seasonal incidence of malaria in the
Limbé River valley of northern Haiti and also the relationship between rainfall and malaria, which is critical to the control of malaria in the region.

\section{MATERIALS AND METHODS}

This study was conducted at a missionary hospital, the Bon Samaritain Hospital (BSH), which is located in the town of Limbé in the Limbé River valley of northern Haiti. The Limbé River valley faces the north coast of Haiti and is surrounded by hills and mountains known as the Massif du Nord. North- 
east trade winds blow moist air in from the Atlantic. The air cools as it rises above the mountains, producing rainfall averaging $200 \mathrm{~cm}$ per year. The high incidence of malaria in the region results from that abundant rainfall, which also helps make the land viable for horticulture and a dense human population. Runoff water into the valley produces marshy areas and ideal breeding conditions for the anopheles mosquito. BSH is one of the largest hospitals in northern Haiti, and because it provides inexpensive services, it plays a pivotal role in the area's health care.

The data compiled in this report was obtained from BSH records for 1975 through 1997 and also from information that had been tabulated by William Hodges, who was director of the BSH from 1958 until his death in 1995.

In this study, the number of cases of malaria was determined from BSH laboratory records of patients showing positive slides for malaria. The laboratory procedure for diagnosing malaria at the hospital did not change in any significant way during the study period. The hospital was open 6 days a week, from Monday through Saturday. Each morning, any patient wishing to see a doctor attended medical triage. People who presented with fevers and no cough, delirium, or aches and pains were given a "malaria ticket," which they took to the laboratory. At the laboratory, the patient's finger was pricked, and two thick smear slides were prepared and stained with Giemsa $(2 \mathrm{~mL}$ Giemsa stain to $35 \mathrm{~mL}$ water). From one to five microscope fields were viewed. The malaria parasite was usually detected in the trophozoite stage, but occasionally the gametocyte stage was seen. The same type of malaria testing was done on nosocomial cases and also on patients who were thought not to have malaria at triage, but who, upon more thorough physical examination in the clinic, were suspect.

Weekly totals for rainfall from 1975 through 1985 were tabulated from small notebooks that Dr. Hodges had kept. He took the measurements daily, including Sundays, on the hospital premises using a homemade rainfall gauge.
Data from World Health Organization (WHO) publications were used to compare the incidence of malaria at BSH with data from all of Haiti for 1975-1996 (5-17).The data comparing rainfall with incidence of malaria was analyzed by Pearson regression analysis using SPSS for Windows v 9 ( $w w w$. SPSS.com).

\section{RESULTS}

\section{Number of malaria cases at BSH, 1975-1997}

Figure 1 shows the annual totals for the Limbé region for 1975-1997 for malaria detected at BSH as compared to WHO data for all of Haiti. In this 23year period, 27078 positive slides for malaria were observed at BSH. The highest number in a single year was 3635 , in 1983, and the lowest number was 54 , in 1975. The data from BSH generally corresponded to $\mathrm{WHO}$ data and showed that both in the Limbé region and in Haiti as a whole malaria has been declining since the mid-1980s, following some 5 years of increasing incidence. However, it also appears that since the mid-1980s, BSH is reporting a greater proportion of the total number of malaria cases for the country as a whole. For example, for the 8-year period of 1977 through 1984, BSH reported an average of $3.3 \%$ of the total number of cases from Haiti. This proportion increased to an average of $7.5 \%$ for the 8 year period of 1985 through 1992.

\section{Cyclical trends and seasonal distribution, 1975-1997}

Figure 2 shows the incidence of malaria at $\mathrm{BSH}$, with the combined total number of cases for 1975-1997 shown for each of the 52 weeks of the year. The incidence of malaria at BSH was seasonal and included a winter peak and a summer peak. The winter peak included 8 weeks in December (weeks 49-52) and January (weeks 1-4). The mid-summer peak included 8 weeks in June and July (weeks 23-30). Taken together, the winter and summer peaks comprised 16 weeks out of each year and accounted for $50 \%$ of the total number of positive slides detected between 1975 and 1997. There were two periods of low incidence: weeks

FIGURE 1. Annual incidence of malaria in the Limbé River valley compared to all of Haiti, 1975-1997

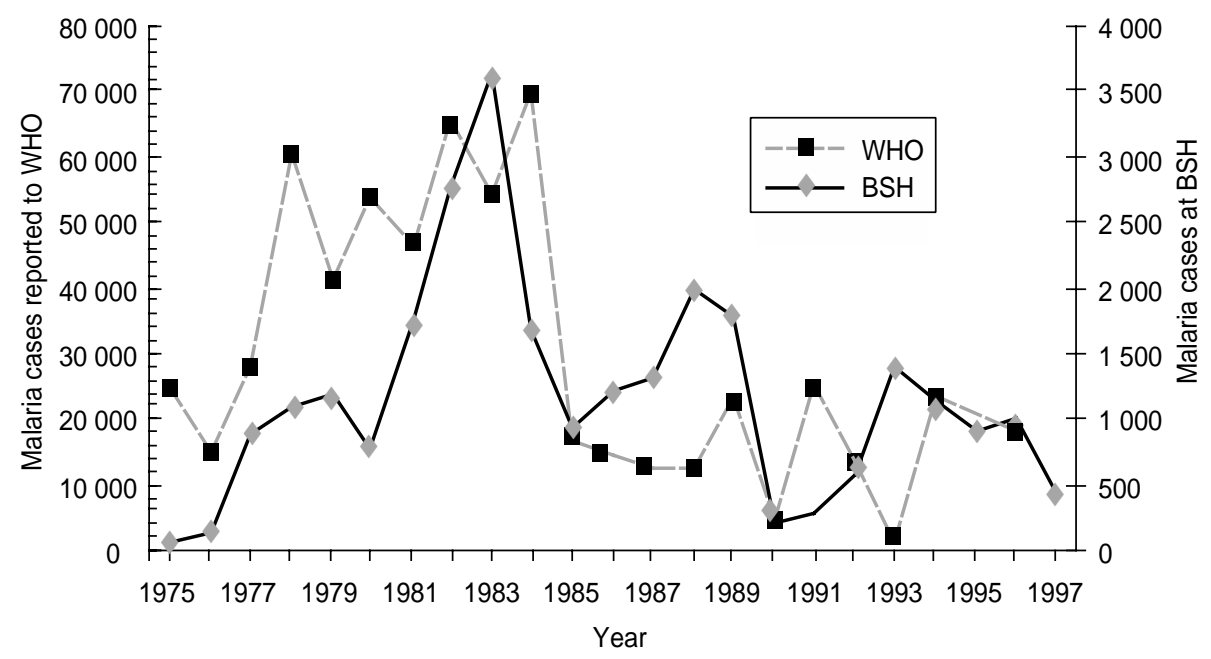

a Data for the Limbé River valley for 1975-1997 are based on number of positive slides recorded by the Bon Samaritain Hospital (BSH). Data for Haiti as a whole are based on number of cases reported to the World Health Organization (WHO data not available for 1995 and 1997). 


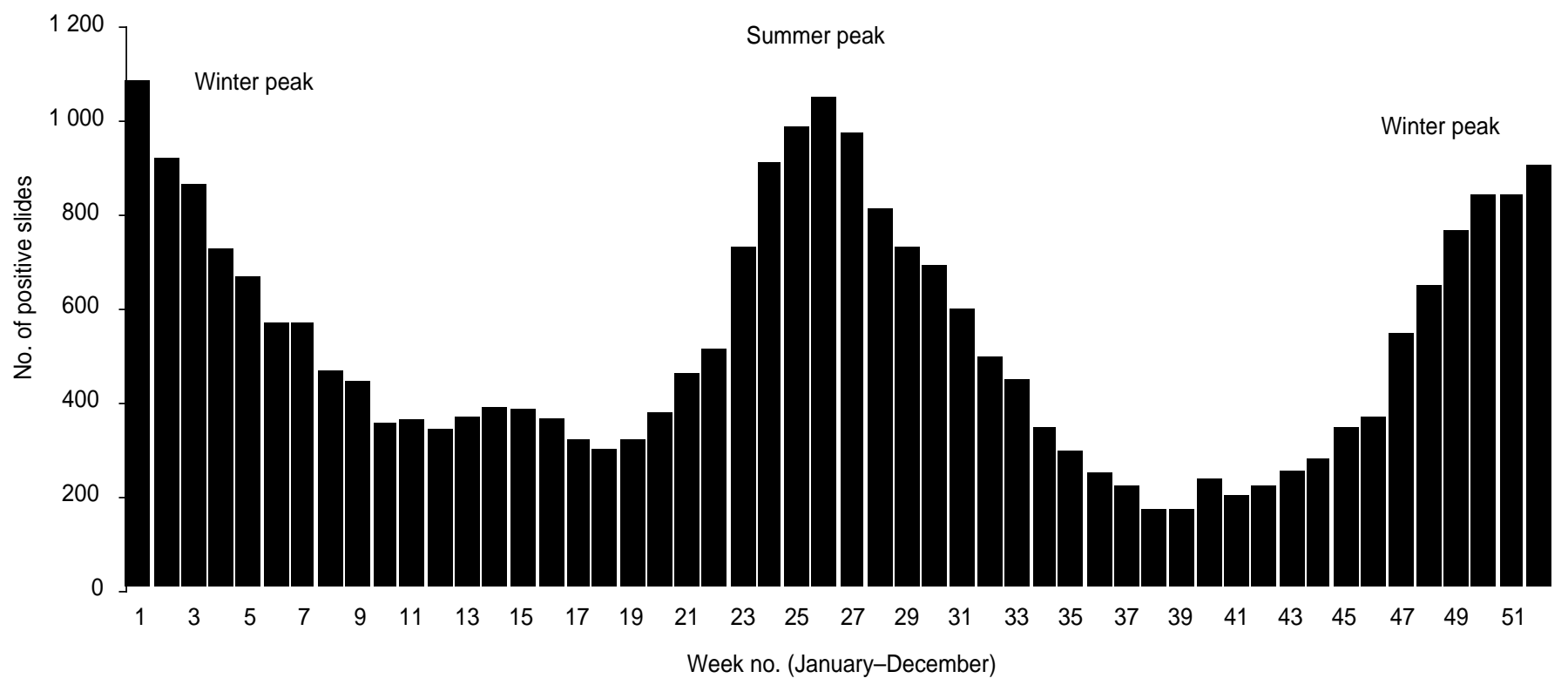

5-22 and weeks 31-48. The periods of lowest incidence were weeks 10-20 and weeks 34-46.

\section{Rainfall and incidence of malaria, 1975-1985}

For the period of $1975-1985$, there was a mean rainfall of $215 \mathrm{~cm} \pm 68 \mathrm{~cm}$ each year in the Limbé River valley and a mean of $1352 \pm 1071$ cases of malaria each year at BSH. Haiti is in a region of hurricanes and tropical storms, which explains the wide variation in rainfall $(142-351 \mathrm{~cm} /$ year $)$ in the region (Figure 3).

There was no significant correlation found between total annual rainfall and incidence of malaria at BSH. However, when the weekly totals for the entire 1975-1985 period were adjusted to allow a lag period between rainfall and incidence of malaria, a significant correlation between weekly rainfall and weekly incidence of malaria became evident (Figure 4 and Table 1). In these calculations, 52 data points were used to compute the Pearson correlation coefficients. There was a significant positive correlation $(P \leq 0.05)$ between rainfall and malaria when the data was adjusted to allow a lag of 6-13 weeks between weekly rainfall and weekly incidence of malaria. The highest correlations were observed when the data were adjusted to allow a lag of 9-11 weeks between rainfall and subsequent malaria (Table 1).

\section{DISCUSSION}

This study shows that malaria is endemic to the Limbé River valley of northern Haiti, with periods of high in- cidence in December and January and in June and July and periods of lower incidence on either side of the mid-summer peak. This seasonal pattern generally coincides with that found in the Artibonite Valley of central Haiti (18).

Rainfall is only one of many factors influencing the transmission and incidence of malaria (19-21). However, it has been previously shown that a strong positive association exists between the incidence of falciparum malaria and rainfall $(21,22)$.

FIGURE 3. Intersection points for annual rainfall (cm) and annual incidence of malaria (positive slides) for specific years at Bon Samaritain Hospital, Limbé, Haiti, 1975-1985

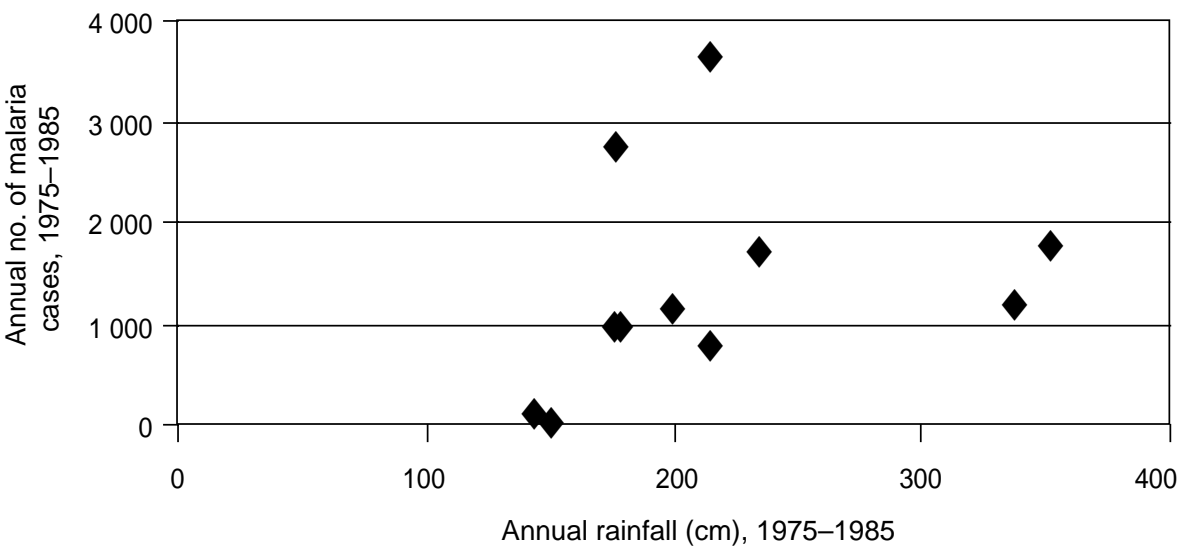



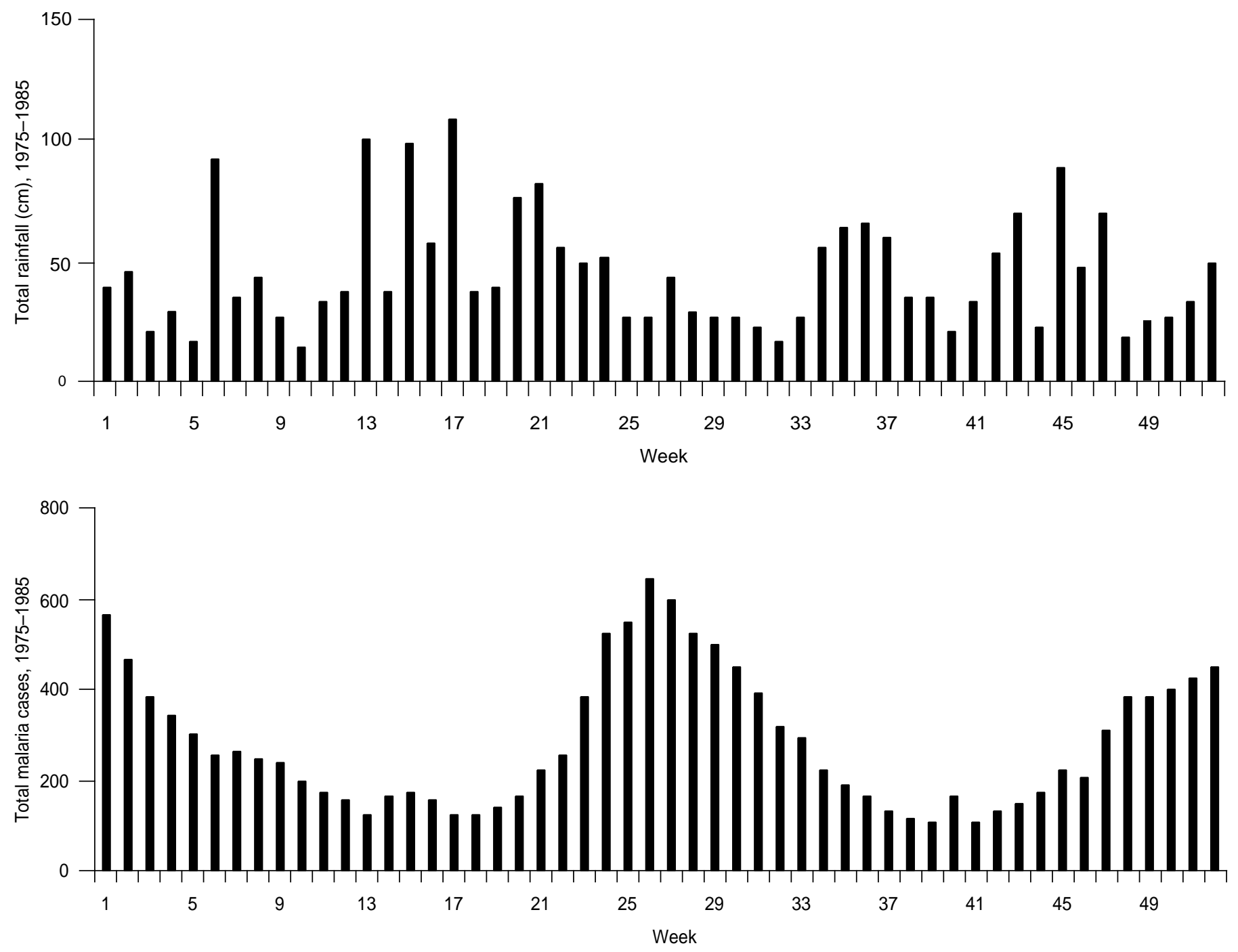

In this study, the correlation between rainfall and falciparum malaria from 1975 through 1985 was significant when the data was adjusted to allow a lag of 6-13 weeks between weekly rainfall and new cases of malaria. The correlation was strongest for a time lag of 9-11 weeks between rainfall and malaria. The time delay between rainfall and increased incidence of malaria is the total time required for the change in larval habitat, caused by rain, to have an effect on humans. After a heavy rain, it may be necessary for water to recede to provide new breeding sites. Further time is needed for larvae to hatch and mature, for the adult female to find an infected host and become infected herself, and for completion of the sexual stage of the falciparum life cycle within the vector. Additional time is required for the infected mosquito to bite an uninfected host. The onset of symptoms in the bitten person and the trip to the hospital and diagnosis of malaria complete the total time period. Estimates for the duration of each of these events in Haiti include 15 days for the pre-imaginal development of Anopheles albimanus, 4-7 days for the gonadotrophic cycle for parous/nulliparous female mosquitoes, and 12 days for the sporogonic cycle for the Plasmodium falciparum parasite in the insect vector (30). Therefore, about 4 weeks are needed for the development of a new generation of infective female insect vectors. Since the symptoms of falciparum malaria develop after an incubation period of approximately 12 days, the total time from the development of breeding sites to the appearance of new malaria cases is about 6 weeks. We observed the lag between rainfall and malaria to be 6-13 weeks. This means that after a period of rain, fresh breeding sites become available immediately and persist for 7 weeks. Since the highest correlations between rainfall and malaria were observed with a lag of 9-11 weeks, optimal breeding sites become available after 3-5 weeks following a rain. Knowledge of the du- 
TABLE 1. Pearson correlation coefficient $(r)$ and significance $(P)$ of the relationship between combined weekly rainfall and incidence of malaria, 1975-1985, Bon Samaritain Hospital, Limbé, Haiti, for different lag periods

\begin{tabular}{ccc}
\hline $\begin{array}{c}\text { Lag period } \\
\text { (weeks) }\end{array}$ & $\begin{array}{c}\text { Pearson } \\
\text { correlation coefficient } \\
(r)\end{array}$ & $\begin{array}{c}\text { Significance } \\
(P)\end{array}$ \\
\hline 0 & -0.369 & .004 \\
1 & -0.276 & .024 \\
2 & -0.165 & .121 \\
3 & -0.061 & .334 \\
4 & +0.005 & .486 \\
5 & +0.099 & .242 \\
6 & +0.243 & .041 \\
7 & +0.307 & .013 \\
8 & +0.414 & .001 \\
9 & +0.463 & $<.001$ \\
10 & +0.471 & $<.001$ \\
11 & +0.458 & $<.001$ \\
12 & +0.381 & .003 \\
13 & +0.306 & .014 \\
14 & +0.218 & .061 \\
\hline
\end{tabular}

ration of these time periods is critical in malaria-control efforts. Knowing the time between rainfall and increased activity of vectors allows for more accurate vector control, and knowing the time delay between rainfall and increased incidence of malaria allows the efficacy of control efforts to be monitored.

Our findings are supported by studies in India and Sri Lanka. In India, researchers observed a 2-week time lag between rainfall and vector abundance (25). Rainfall also increased the rate at which humans were bitten (26). In the dry zone of Sri Lanka, where malaria is also endemic, a 2-month time lag was reported between rainfall and increased malaria (23). Due to the nature of biological processes and the degree to which they depend on such physical factors as altitude, topography, temperature, surface water, vegetation, and humidity (24), it seems probable that the time lag between rainfall and malaria would be somewhat region specific.

Haiti has endured political, social, and environmental turmoil. Such instability necessarily affects the health infrastructure and malaria reporting capabilities. A significant drop in the number of cases reported to the WHO between 1988 and 1993 coincided with a time of intense political strife. This drop was thought to be the result of underreporting (27). Bonnlander et al. (18) addressed the same question using data from the Albert Schweitzer Hospital in central Haiti. Their study, however, supported the official report that malaria in Haiti was, overall, in decline, as did our study of the Limbé River valley. However, underreporting in other parts of Haiti may explain the apparent increase in the proportional share of malaria cases reported by $\mathrm{BSH}$, from an average of $3.3 \%$ for the $1977-1984$ period to $7.5 \%$ for the 1985-1992 period.

Limitations of our study were rather fundamental. The data analyzed did not include the total number of slides tested at BSH during the study period; this information was not available. Consequently, slide positivity rates could not be calculated, and the results are based only on the number of slides found to be positive, rather than the more meaningful positivity rate.

The second limitation is a problem systemic to Haiti, namely the degree of accuracy of microscopic malaria diagnosis. A study conducted in 1995 testing this accuracy found the overall sensitivity of microscopic diagnosis to be
$83.6 \%$, specificity to be $88.6 \%$, and the predictive value of a positive slide to be only $22.2 \%$ (27). While that study found that the microscopic diagnosis of malaria in Haiti was generally unreliable, we believe that BSH, as a wellestablished health facility, might fare better than the national average, and that the degree of $\mathrm{BSH}$ diagnostic accuracy would have been fairly constant throughout the study period, allowing general trends to be analyzed with some confidence. It must also be remembered that thick-smear slides are the only significant laboratory malaria diagnostic method currently used in Haiti, and thus the only laboratory diagnostic data available for study.

The Limbé River valley is a prime candidate for a concentrated effort of malaria control. The area is relatively small, has a well-established health facility, and the history of malaria is now well documented. This study shows that a seasonal pattern of malaria distribution exists in the valley and that the relationship between rainfall and malaria incidence is best explained by a time lag of 9-11 weeks.

A further area of interest involves the geographic stratification of malaria within the Limbé River valley. It is common local knowledge that Bas Limbé, a small town close to Limbé, is the major focus of malaria in the area. For example, in $199743 \%$ of the positive slides diagnosed at $\mathrm{BSH}$ were obtained from people living in Bas Limbé (Vanderwal, unpublished data). The nature of malaria incidence in Haiti, namely the phenomena of seasonal and focal distribution (28) and the low overall prevalence of malaria, necessitates a focus on regional epidemiological situations (27). Efforts to control or interrupt malaria transmission ought to be guided by epidemiological services (29), and an essential element of that is an area-specific understanding of the relationship that rainfall has with both vector density and malaria incidence.

Acknowledgements. We thank the administrators of l'Hôpital Bon Samaritain for being such helpful resources. We are also grateful to Joanna Hodges 
for granting us permission to use unpublished data recorded by William Hodges. We also express our thanks to
Phuc Nguyen-Dinh of the U.S. Centers for Disease Control and Prevention for offering insightful comments through correspondence, and to Jodi VanderWoude and Darcy Kehler for their expert technical assistance.

\section{REFERENCES}

1. Yarseth T, Duverseau, RM, Arturo S-I, Rogers HM, Phuc N-D. Monitoring of chloroquine sensitivity of Plasmodium falciparum in Haiti, 1981-1983. Am J Trop Med Hyg 1986;35(3): 459-464.

2. World Health Organization. World malaria situation 1990. World Health Stat Q 1992;45: 257-266.

3. World Health Organization. World malaria situation 1983. World Health Stat Q 1985;38: 193-231.

4. Malaria control in the Americas: a critical analysis. Bull Pan Am Health Organ 1986; 20(3): 304-320.

5. World Health Organization. Wkly Epidemiol Rec 1977;52(14):128.

6. World Health Organization. Wkly Epidemiol Rec 1977;52(42):336-337.

7. World Health Organization. Wkly Epidemiol Rec 1979;54(14):116-117.

8. World Health Organization. Wkly Epidemiol Rec 1980:55(27):202-203.

9. World Health Organization. Wkly Epidemiol Rec 1981;56(21):162-163.

10. World Health Organization. Wkly Epidemiol Rec 1982;57(31):234.

11. World Health Organization. Wkly Epidemiol Rec 1983;58(26):198.

12. World Health Organization. Wkly Epidemiol Rec 1999;74(32):265-270.

13. World malaria situation, 1985. World Health Stat Q 1987;40:142-170.
14. World malaria situation, 1988. World Health Stat Q 1990;43:68-78.

15. World malaria situation, 1990. World Health Stat Q 1992;45:257-265.

16. World malaria situation in 1993, part II. Wkly Epidemiol Rec 1996;71:25-29

17. World malaria situation in 1994, part II. Wkly Epidemiol Rec 1997;72:277-283

18. Bonnlander H, Rossignol AM, Rossignol PA. Malaria in central Haiti: a hospital-based retrospective study, 1982-1986 and 1988-1991. Bull Pan Am Health Organ 1994;28(1):9-16.

19. Breeland SG. Studies on the ecology of Anopheles albimanus. Am J Trop Med Hyg 1972;21(5):751-754.

20. Akhtar R, McMichael AJ. Rainfall and malaria outbreaks in western Rajasthan. Lancet 1996;349(9039):1457-1458.

21. Gupta R. Correlation of rainfall with upsurge of malaria in Rajasthan. J Assoc Physicians Ind 1996;44(6):385-389.

22. Bouma MJ, Dye C, van der Kaay HJ. Falciparum malaria and climate change in the Northwest Frontier Province of Pakistan. Am J Trop Med Hyg 1996;55(2):131-137.

23. Van der Hoek W, Konradsen F, Perera D, Amerasinghe PH, Amerasinghe FP. Correlation between rainfall and malaria in the dry zone of Sri Lanka. Ann Trop Med Parasitol 1997; 91(8):945-949.

24. Woube M. Geographical distribution and dramatic increases in incidences of malaria: con- sequences of the resettlement scheme in Gambela, SW Ethiopia. Indian J Malariology 1997;34:140-163.

25. Prakash A, Bhattacharyya DR, Mohapatr PK, Manhanta J. Seasonal prevalence of Anopheles dirus and malaria transmission in a forest fringed village of Assam, India. Indian J Malariology 1997;34:117-125.

26. Onori E, Grab B. Indicators for forecasting of malaria epidemics. Bull World Health Organ 1980;58:91-98.

27. Kachur SP, Nicolas E, Jean-Francois V, Benitez A, Bloland PB, Saint Jean Y, et al. Prevalence of malaria parasitemia and accuracy of microscopic diagnosis in Haiti, October 1995 Rev Panam Salud Publica 1998;3(1):35-39.

28. Duverseau YT, Jean-Francois V, Benitez A. Formation pour la prévention de la malaria: diagnostic de la malaria. Port-au-Prince, Haiti: Pan American Health Organization; 1989. (PAHO/HAI/89/023)

29. Najera, JA. Malaria and the work of the WHO. Bull World Health Organ 1989;67:229-243.

30. Molez JF, Desenfant P, Jacques JR. Bio-écologie en Haïti d'Anopheles albimanus Wiedemann, 1820 (Diptera: Culicidae). Bull Soc Pathol Exot 1998;91(4):334-339.

Manuscript received on 3 August 1999. Revised version accepted for publication on 21 December 1999.

RESUMEN En el valle del río Limbé en el norte de Haití se llevó a cabo un estudio en el Hospital Bon Samaritain (HBS) para determinar el número total de casos y el comportamiento cíclico de la malaria desde 1975 hasta fines de 1997. En él también se examinó la La malaria en el valle del río
Limbé en el norte de Haití:
estudio retrospectivo en un
hospital, 1975-1997 relación entre la pluviosidad y la malaria de 1975 hasta fines de 1985 y se comparó la incidencia de la enfermedad en ese hospital con las tendencias generales observadas en Haití de 1975 hasta fines de 1996, según informes de la Organización Mundial de la Salud (OMS).

En el período de 1975-1997, 27078 casos de malaria fueron diagnosticados en el HBS; $50 \%$ de ellos se presentaron en un período de 16 semanas en el año, durante un "pico" estival en junio y julio y durante un pico invernal en diciembre y enero. Para el período de 1975 a 1985, no se observó una correlación significativa entre la incidencia de malaria y la pluviosidad anual. La correlación más fuerte se produjo entre la pluviosidad semanal y la incidencia semanal de malaria cuando los datos se agruparon a manera de dejar un espacio de 9 a 11 semanas entre las lluvias y los casos nuevos de malaria. Este período de tregua se atribuye al tiempo necesario para la formación de nuevos criaderos después de las lluvias, a los ciclos vitales del mosquito Anopheles albimanus y del parásito Plasmodium falciparum y al período de incubación de la malaria de tipo falciparum.

La incidencia de malaria en el valle del río Limbé mostró una tendencia similar, en términos generales, a la observada en todo Haití y coincidió con informes de la OMS al efecto de que en este país la malaria ha venido declinando desde mediados de los años ochenta.

Este estudio, al delinear las tendencias estacionales propias de la malaria en el valle del río Limbé y la relación entre la pluviosidad y la malaria durante un largo período, permite medir la efectividad de las iniciativas de control de la malaria en esa región. 